\title{
Scientific and technological journals in Vietnam: the current state and direction of development
}

\author{
Banh Tien Long ${ }^{1}$, Nguyen Duc Toan ${ }^{1,2}$ \\ ${ }^{1}$ School of Mechanical Engineering, Hanoi University of Science and Technology, Hanoi; ${ }^{2}$ Department of Mechanical \\ Engineering, Hungyen University of Technology and Education, Hungyen, Vietnam
}

Abstract

Vietnam is on its way to becoming a more developed country and more integrated into the global community. One of the most important key factors for development is science and technology. Scientific publications bring the most up-to-date information to scientists, researchers, and society. The quality of Vietnam's scientific journals should be increased to international level. Also, the number of high quality articles published in international journals from Vietnam is limited compared to the number of researchers in Vietnam. There is still no Vietnamese journal indexed in Web of Science up to January 2015; while, three journals has been indexed in Scopus. This article discusses the current scenario of scientific and technological journals in Vietnam and the trend of development to international level.

Keywords:

Academies and institutes; Publications; Research personnel; Science; Vietnam

\section{Introduction}

Received: December 15, 2014

Accepted: January 28, 2015

Correspondence to Banh Tien Long long.banhtien@hust.edu.vn

ORCID

Banh Tien Long

http://orcid.org/0000-0003-1669-4791

Nguyen Duc Toan

http://orcid.org/0000-0001-9619-4476
Vietnam has hundreds of scientific and technological journals covering hundreds of topics. They have not been indexed in Web of Science, but at least three of them have been indexed in Scopus up to January 2015. The journal evaluation process is usually based on a point scale established by the organization, the State Council for Professor Title. The journal, Advances in Natural Sciences: Nanoscience and Nanotechnology (eISSN: 2043-6262, http://iopscience.iop. org/2043-6262/) published by IOP Publishing and the Vietnam Academy of Science and Technology (VAST), received the highest points in the field of chemistry. Vietnamese societies of science and technology, ministries, research institutes, and universities have published most of the journals [1]. Many universities produce their own journals, most of which are evaluated by the State Council for Professor Title, with the highest point [2]. For example, the Journal of Science and Technology at Technical Universities (Tạp chí Khoa học và Công nghệ các trường 


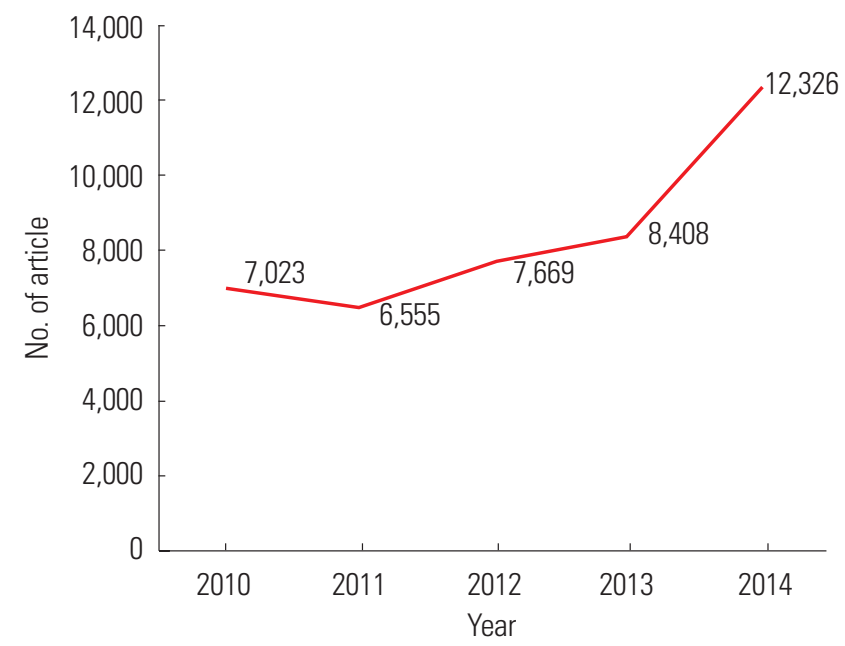

Fig. 1. The number of articles published in scientific and technological journals in Vietnam from 2001 to 2005.

đại học kỹ thuật, ISSN: 0868-3980, http://www.vjol.info/index.php/DHBK) is published by the Hanoi University of Science and Technology and other 6 universities. The question remains: how can we maintain the scientific quality of journals? In this article, the situation of some top-ranking journals and elaboration of science editors to promote their journals will be introduced. Those may be able to provide the hint for local journal development in developing countries.

\section{Journals in Vietnam as a Work of Valuable Achievement for Scientific Work}

About 200 scientific journals from universities and 63 ones from provincial departments were presented at the 27th annual Interdisciplinary Council for Professor Titles of Vietnam, 2014. Out of them, many titles were equipped with ISSN (International Standard Serial Numbers). It is possible since ISSN center of the Ministry of Information and Communication of Vietnam Government provides ISSN for new journal. However, a few journals were peer reviewed. Articles published in those accredited journals were recognized as valuable achievement for professors and researchers. Number of articles published in domestic scientific journals according to year was presented in Fig. 1.

\section{Case of the Journal of Science and Technology at Technical Universities}

The process of start and development: It was launched at the beginning of early 1995 [3]. On October 6, 1995, delegates of leaders from four universities agreed to change the title Sci- ence and Technology Issues to present title. The four universities involved were the Hanoi University of Science and Technology, the Da Nang University of Technology, Ho Chi Minh University of Technology, and the University of Technical Education, Ho Chi Minh City. Afterwards, Thai Nguyen University of Technical Industry, the Posts \& Telecommunications Institute of Technology, and the University of Economy and Technical Industry also participated in this title. Thus, seven leading technical universities in Vietnam now publish and distribute this title.

Legal basis: There was an agreement among the technical universities to launch the journal on October 6, 1995 with present title. There was a Decree of the Minister of Education \& Training on January 2, 1996. The publication license was granted by the Ministry of Culture and Information on December 13, 1995, that has been renewed regularly.

Number of articles: In 15 years, the journal has published 79 volumes with 1,700 articles across all fields within science and technology area. Since 2009, the journal has published six issues. Out of six issues, two are only in English. Proportion of each topics was as follows: electrical engineering, 20\%; mechanical engineering, $18 \%$; chemistry, $16 \%$; textiles, $10 \%$; and other topics $36 \%$.

Aims and goal: Its aims are to publish research findings, disseminate new products, spread knowledge in the areas of science and technology, and to facilitate technology transfer from the engineering school, the ministry, the institutes, the research centers, the rural offices of the Department of Science and Technology, and cities around the country. Languages are Vietnamese as well as English at now. The urgent goal is to change the language to English only to provide the more visibility of the scientific work from Vietnam.

Prestige of the title: The journal has been highly appreciated by the Science Board of Vietnam, which provides support for training $\mathrm{PhD}$ students, and assigns research topics. Articles have been appreciated highly by the State Council for Professor Title.

Problems in publishing the journal were as follows: uneven quality of articles; part-time editorial work; use of email for manuscript transfer; some low quality peer reviews; non-professional journal web site; and multi-disciplinary contents.

Further requirements are needed as follows: employment of professional managing editor or manuscript editor; improvement of peer review process and training of peer review; invitation of international researchers as peer reviewers; timeliness of publication; recruitment of novel content of manuscripts; international diversity of an editorial board; conversion to English only journal from 2016; and inclusion of title to international citation databases such as Web of Science or Scopus. 


\section{Cases of Publications Supported by the Vietnam Academy of Science and Technology}

Three journals, Advances in Natural Sciences: Nanoscience and Nanotechnology, Vietnam Journal of Mathematics, and Acta Mathematica Vietnamica are part of a project of Vietnam Academy of Science and Technology which aims to improve the quality of journals according to international standards $[3,4]$.

Advances in Natural Sciences: Nanoscience and Nanotechnology It was launched from 2000. This journal made a publishing contract with British press houses, IOP Publishing. Since October 28, 2013, it has published four issues online according to international standards. Each issue features 20 articles, reviewed by two researchers. A total of 80 articles were published and the authors were from the following countries: Vietnam, 42; Asia and Australia, 26; Europe, 8; and USA, 4. According to the announcement of IOP Publishing, the international scientific community has downloaded the articles from this journal. IOP Publishing provided statistics of access to the title for the first 9 months of 2013 (Fig. 2). The access number was 109,448 over the 9-month period. It is now indexed in Scopus.

Vietnam Journal of Mathematics (pISSN:2305-221X, eISSN: 305-2228, http://www.springer.com/mathematics/ journal/10013)

In Vietnam, this journal has achieved a high position in the field of mathematics, containing articles with high quality research output. Thus far, Springer Publishing Company has published four issues a year. Special issues were released to encourage prestigious mathematicians from around the world to

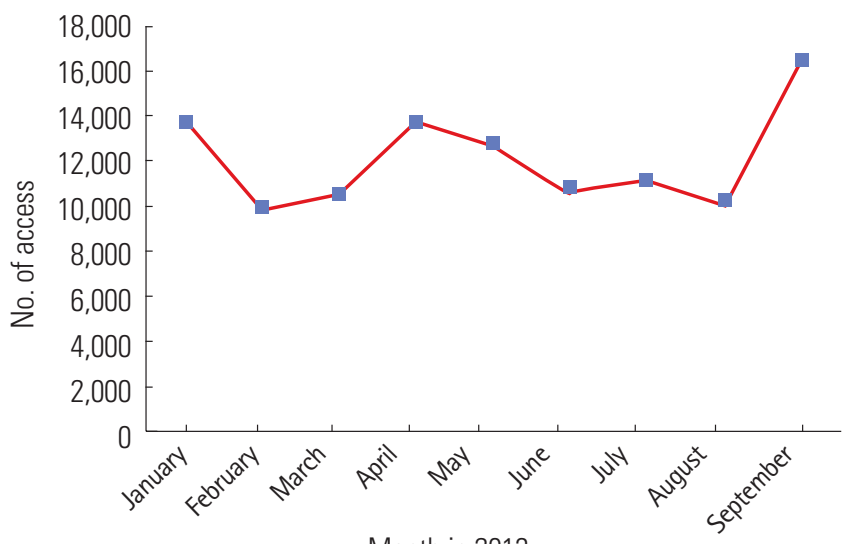

Month in 2013

Fig. 2. The access numbers for the first 9 months of 2013 to Advances in Natural Sciences: Nanoscience and Nanotechnology contribute. In 2013, this title issued a call for papers on four special subjects, and received contributions from many mathematicians in various countries including Japan, France, Germany, and the United States. It received more papers in 2013 than in 2012. It was launched from 2009. Figs. 3 and 4 show the fate of manuscripts after peer-review and the countries of authors (Vietnamese or foreign) that it published between 2009 and November 20, 2013. All manuscripts were submitted and processed via online system that Springer Publishing Company designed for this title. The role of the editorial board was strengthened by making the board be responsible for handling manuscripts and critical comments. It began to be indexed in Scopus from October 10, 2013.

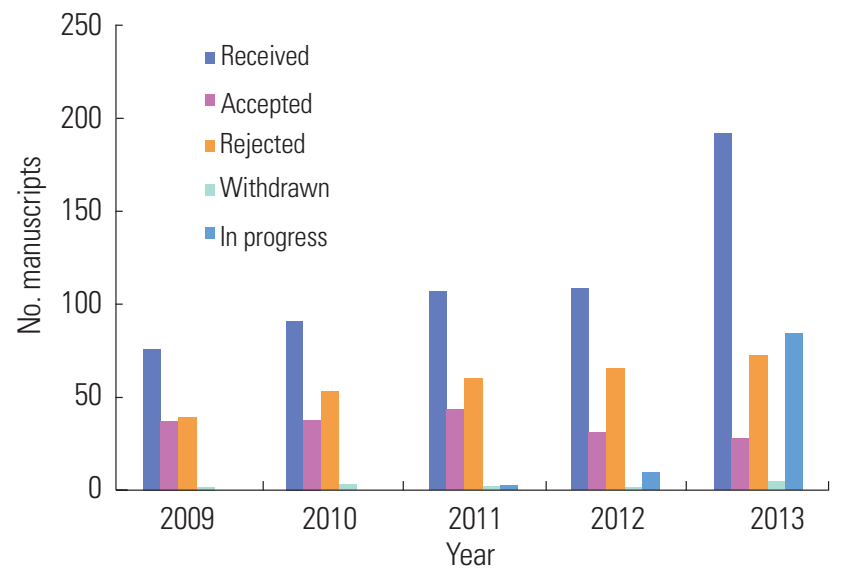

Fig. 3. Fate of peer reviewed manuscripts submitted to Vietnam Journal of Mathematics received from 2009 through November 20, 2013.

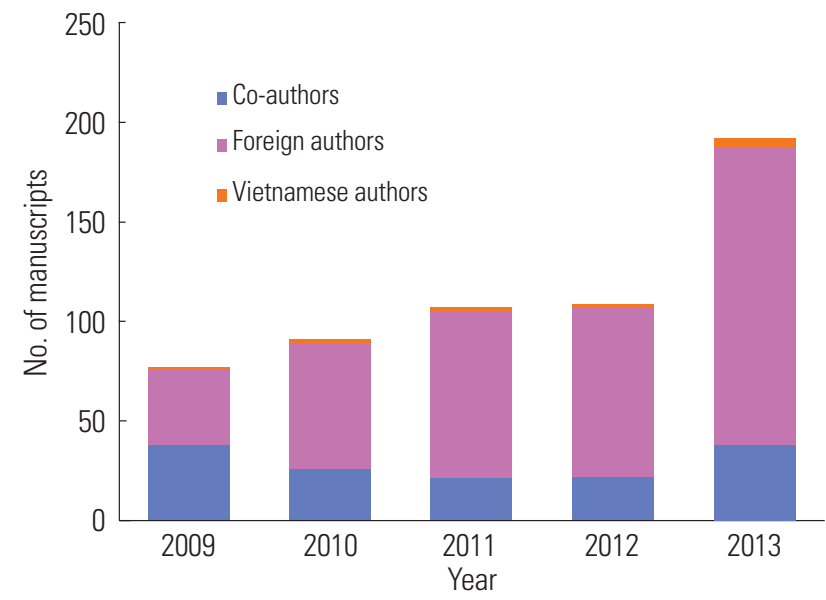

Fig. 4. Number of manuscripts submitted to Vietnam Journal of Mathematics received from 2009 through November 20, 2013 according to authors' countries. 


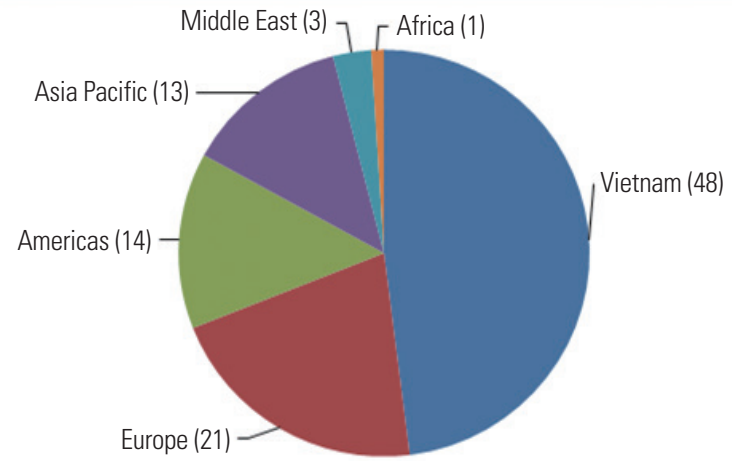

Fig. 5. Continents of reviewers for Acta Mathematica Vietnamica in 2014 (\%).

\section{Acta Mathematica Vietnamica (pISSN: 0251-4184, eISSN: 2315-4144, http://www.springer.com/mathematics/ journal/40306)}

It has been published with Singapore office of Springer Publishing Company from 2013. Until February 2015, it has published 108 articles online. The ratio of papers submitted by foreign authors increased in 2013 (from January through November 2013 ) by $86 \%$. The ratio of work reviewed by foreign mathematicians also rose each year, which increased the quality of the articles (Fig. 5). It is the first scientific journal in Vietnam to be accepted by the Scopus Content Selection and Advisory Board in 2012.

\section{Conclusion}

Development of science and technology has played key role in helping Vietnam become an industrialized country. Scientific journals are doing a good job of communicating, disseminating, and publishing new discoveries by universities, research institutes, and companies. Also, it brings Vietnamese and foreign scientists work together. Almost all journals in Vietnam are changing and trying to improve their quality. They include the Journal of Science and Technology at Technical Universities published by seven universities. Another three journals pub- lished by the Vietnam Academy of Science and Technology were also good examples. The editorial board members are investing their competence in these periodicals in order to enhance the journal quality up to international level. In addition, critical peer reviews was stressed to improve the quality of the journals. With those efforts by editors, more number of Vietnamese journals may be eligible to be indexed in international citation databases such as Scopus or Web of Science. This article may be the first leap to develop scientific and technological journals in Vietnam and to promote their integration with the international scientific community.

\section{Conflict of Interest}

No potential conflict of interest relevant to this article was reported.

\section{Acknowledgments}

This work is supported by a travel grant from the Korean Federation of Science and Technology Societies, the Government of the Republic of Korea (2014).

\section{References}

1. Ministry of Science and Technology. Science and technology in Vietnam in 2007. Hanoi: Ministry of Science and Technology; 2007.

2. Prime Minister of Vietnam. Decision no. 174/2008/QdTTG on promoting the criteria and procedures for appointing and dismissing associate professors and professors (2008 Dec 12). Hanoi: Vietnamese government; 2008.

3. Central Propaganda Department. The situation of media activities of the Vietnam Academy of Science and Technology. Hanoi: Central Propaganda Department; 2014.

4. Hien PD. A comparative study of research capabilities of East Asian countries and implications for Vietnam. High Educ 2010;60:615-25. http://dx.doi.org/10.1007/s10734010-9319-5 